\title{
Tradução intralinguística, estratégias de equivalência e acessibilidade textual e terminológica
}

\section{Intralingual translation, equivalence strategies and textual and terminological accessibility}

Maria José Bocorny Finatto* Lucas Meireles Tcacenco* 
Resumo: 0 artigo situa a simplificação de textos especializados como tradução intralinguística. À luz de estratégias de equivalência descritas por Baker ([1992] 2018), contrastam-se textos originais e simplificados de um corpus composto por textos que acompanham experimentos em um museu de ciências e tecnologia do Brasil. Do pareamento entre textos-fonte considerados complexos, escritos para público leigo em geral, e suas versões lexical e sintaticamente adaptadas para público infanto-juvenil, verificam-se estratégias de equivalência nas simplificações. Por fim, apresentam-se ponderações teóricas e metodológicas para a simplificação de textos de temática científica em meio aos estudos de Tradução, Terminologia e Linguística de Corpus.

Palavras-chave: Tradução intralinguística; Simplificação textual; Acessibilidade Textual e terminológica; Textos de museus; Linguística de Corpus.

Abstract: The article presents the simplification of specialized texts as a kind of intralingual translation. In light of the equivalence strategies described by Baker (2018), the original and simplified versions of texts that accompany experiments in a science and technology museum in Brazil are compared. After the analysis of complex source texts written for the general public, and their lexically and syntactically adapted versions for children and adolescents, it has been found that some of Baker's equivalence strategies can also be applied to simplifications. Finally, theoretical and methodological considerations are presented for the simplification of scientific texts in Translation Studies, Terminology and Corpus Linguistics.

Keywords: Intralingual translation; Textual simplification; Textual and terminological accessibility; Museum texts; Corpus Linguistics.

TradTerm, São Paulo, v.37, n. 1, janeiro/2021, p. 30-63

Número Especial - Linguística de Corpus www.revistas.usp.br/tradterm 


\section{Introdução}

Este artigo revisa concepções sobre tradução, com Jakobson ([1969], 2003), Zethsen (2009; 2016), Toury (1995), Eco (2007) e Travaglia (2003), para situar a simplificação de textos especializados para leigos como um tipo de tradução, a tradução intralinguística ( $\mathrm{Tl})$. Para tanto, analisa textos de temática científica, em português, anexos a objetos de um museu de ciências e tecnologia, frente às suas versões simplificadas, também em português, feitas para alunos do Ensino Fundamental de escolas públicas.

Para refletir sobre essa reescrita, tomamos as ideias de Zethsen (2009, 2016) sobre a TI. A elas, associamos estudos sobre acessibilidade textual e terminológica (doravante ATT) (FINATTO; MOTTA 2019). E, aproximando simplificação e $\mathrm{Tl}$, verificamos como estratégias de equivalência em tradução - entre línguas diferentes, propostas por Baker ([1992] 2018) - aplicam-se nesse cenário. A reflexão inclui a construção, em curso, de um corpus paralelo, como preconizado em Linguística de Corpus (VIANA; TAGNIN 2015), mas do tipo 'complexo => simplificado'.

Este artigo também visa ilustrar o processo de alinhamento entre originais e simplificações. Outro objetivo é buscar padrões das (re)escritas e opções para aperfeiçoá-las, em suas diferentes etapas e versões.

Antes de prosseguir, um alerta: não incluímos, nesta reflexão, outros materiais simplificados ou adaptados, como edições literárias para leitores em fase de letramento, geralmente usadas em ensino de línguas. Também não trataremos dos corpora pareados no tipo complexo-simples, já disponíveis para o português, produzidos em pesquisas de Processamento da Linguagem Natural (PLN), nem de simplificações feitas por computador e abonadas por pessoas. Isso não significa desconsiderar o valor desses trabalhos, como os que já exploraram padrões e avaliações de simplificação (CASELLI ET AL. 2009; Hartmann et al. 2016 e Alva-MANCHego 2020) ou os estudos fundadores do Projeto PorSimples, com adaptação de jornais para crianças, e a ferramenta SIMPLIFICA (ALUísIO; GASPERIN 2010), para a escrita simplificada em português.

Sem ser inovador, nosso corpus traz diferentes versões, tentativas ou fases de simplificação de um mesmo texto-fonte. Ao expô-las, como etapas de

TradTerm, São Paulo, v.37, n. 1, janeiro/2021, p. 30-63 Número Especial - Linguística de Corpus www.revistas.usp.br/tradterm 
tradução, queremos compartilhar acertos, erros, excessos e licenças em meio a uma nova modalidade de trabalho profissional com textos especializados, terminologias e modos de dizer em ciências. Buscamos também, assim, dividir experiências sobre a construção desse corpus.

A seguir, neste texto, temos: a) uma revisão de concepções sobre tradução e sobre TI; b) dados do corpus inicial e do corpus em produção; c) uma verificação de uso de estratégias de equivalências nas simplificações. Por fim, refletimos sobre a simplificação como um tema de estudos.

\section{Da tradução à simplificação de textos}

A tradução pode ser entendida sob diferentes perspectivas. Conforme Heidermann (2010: 11), a variedade de aspectos em teorias sobre tradução é quase infinita. Eco (2007), por exemplo, confirma tal diversidade ao compartilhar suas experiências como tradutor e autor. Igualmente, em Benedetti e Sobral (2003), com 'conversas' com tradutores, há pluralidades. Entre essas, a compreensão do tradutor como um leitor-autor.

Com essa compreensão, neste artigo, restringimo-nos ao tema da Tradução no âmbito dos Estudos da Linguagem (EL). Assim, vemos a tradução, e também a TI, como uma atividade de leitura-autoria realizada por um interlocutor-locutor (BENEDETTI; SOBRAL 2003: 203-204).

Trataremos a simplificação como uma leitura e processo de escrita autoral, desdobrado em categorias ou situações de comunicação. Esse processo visa à promoção da ATT (FINATTO; MOTTA 2018), condição que corresponde a um ideal de bom funcionamento do texto que acolhe diferentes tipos de leitores, conforme suas necessidades.

Um texto será acessível, no seu todo, se apresentar informações de forma clara não só para um público específico, conseguindo prever diferentes diálogos. Essa condição aplica-se mesmo a artigos científicos, que muitas vezes precisam ultrapassar um direcionamento muito pontual. É o caso, por exemplo, nestes tempos de pandemia, de um artigo sobre COVID-19, escrito por um infectologista, que precisará ser (bem) entendido por um historiador e

TradTerm, São Paulo, v.37, n. 1, janeiro/2021, p. 30-63

Número Especial - Linguística de Corpus www.revistas.usp.br/tradterm 
que receberá uma 'tradução simplificada', feita por um jornalista. Prever 'outros' leitores e acolhê-los, já desde a primeira escrita do texto, é promover a ATT.

\subsection{Situando a TI}

Nos EL, a 'tradução' é produto, processo ou a ação acrescida de seu produto (MUNDAY 2012). Pode ser vista também como tomada de decisão, reescrita entre textos em uma língua-fonte e uma língua-alvo, como dinâmica de autoria e de subjetividades que envolvem, entre vários recursos, transposição, correspondência, recriação, transcriação ou desconstrução. Há também a tradução como retextualização (TRAVAGLIA 2003).

Entre vários entendimentos, há os que extrapolam a concepção usual da transposição entre línguas diferentes, e abrigam a tradução intersemiótica. Essa é a tradução que mobiliza diferentes tipos de signos e linguagens, abarcando elementos linguísticos e não linguísticos. Ocorre, por exemplo, quando se traduz a ambiência dos quadros de um pintor para o formato de um romance ou nos processos de áudio-descrição para pessoas cegas.

No cenário dos EL, Jakobson (1896-1982) legou-nos, entre tantas reflexões, uma distinção 'clássica' de três tipos 'básicos' de tradução, que inclui a TI. Para Jakobson ([1969] 2003), temos: a tradução intersemiótica, já citada; a interlinguística, que diz respeito à transposição de uma língua para outra; e, a TI, que envolve reformulação dentro de uma mesma língua.

Nos anos 80, Derrida (1903-2004), com a ideia de 'desconstrução', refaz a tipologia de Jakobson. Ao questionar tradução como 'transporte', reflete sobre autoria, criação, subjetividades e escolhas. Para ele, a TI seria aquela que "interpreta signos linguísticos por meio de outros signos da mesma língua" (DERRIDA [1985] 2006: 23). Sua visão de interpretação, como acontece com grandes pensadores, é peculiar. Mas, para Eco (2007: 265-296), a TI não será, jamais, tradução. É, sim, e 'apenas' interpretação. Isso porque, como defende, “interpretar não é traduzir" (Eco 2007: 265-296). Ao equivaler interpretação intralinguística e reformulação, o que entende como paráfrase, Eco assevera: "[o] fato de que reformulação não é uma tradução pode ser

TradTerm, São Paulo, v.37, n. 1, janeiro/2021, p. 30-63 Número Especial - Linguística de Corpus www.revistas.usp.br/tradterm 
facilmente demonstrado" (ECO 2007: 281, grifos nossos).

Por prestígio ou motivações culturais, a tradução entre pares de línguas, como categoria ampla, tem canalizado esforços de compreensão. Prova disso é outra consideração de Jakobson, que a traz como "tradução propriamente dita" (JAKOBSON, [1959] 2000), ou a 'tradução normal'.

Ao retomar Jakobson e as ideias de tradução de Toury (1995), Zethsen (2009; 2016), para nós, é uma autora-marco. Isso porque defende a legitimidade da TI em meio aos Estudos da Tradução. Para ela, a TI é uma necessidade (grifo nosso) de transposição de uma barreira interna da língua, concretizada pela reescrita entre diferentes variedades dessa língua (ZETHSEN 2016: 693). Conforme defende, a simplificação ou adaptação de um textofonte sobre um tema altamente especializado é algo que deveria merecer também a atenção dos estudiosos da Tradução. Afinal, a TI, como salienta, é um tema que tem sido descartado ou subestimado.

Não obstante, no Brasil, a TI já havia sido acolhida. Em 1984, Tarallo (TARALlo APUD MENDES 2009: 1162), desde um viés sociolinguístico, caracterizoua como uma equivalência entre registros. A noção de registro ancorava a sua compreensão sobre a TI e é bastante útil ainda hoje.

Ao produzir recursos para apoiar simplificações de textos em temas de Saúde para trabalhadores de escolaridade limitada, concordamos com Zethsen (2009; 2016) quando compara a TI com a ultrapassagem de uma barreira. Não raro, a barreira extrapola o 'interno'. Afinal, tentamos aproximar, via linguagem, pessoas e comunidades com diferentes relações com os próprios conhecimentos e/ou com a falta deles. Nesse aspecto, pensar em registros distintos, recuperando Tarallo (1984), ilumina nossa busca de 'pontes' para a ATT.

Conforme Zethsen (2016: 693-694), a TI inclui, entre outros, os seguintes tipos:

- TI Dialetal: caso de legendas de filme apresentadas em determinado dialeto que é traduzido (ou adaptado) para a variedade padrão da língua em que se insere o dialeto.

TI Diacrônica: situação da reescrita "atualizada", em versões em língua moderna, como a que encontramos para textos da literatura de TradTerm, São Paulo, v.37, n. 1, janeiro/2021, p. 30-63 Número Especial - Linguística de Corpus www.revistas.usp.br/tradterm 
Shakespeare ou Chaucer.

- TI Intergenérica: reescrita de textos especializados para um leitor leigo.

Essas três instâncias relacionam-se com a promoção da acessibilidade da informação, que deve chegar ao leitor-destinatário de forma 'customizada', para facilitar a compreensão. Nessa classificação, a TI Intergenérica, embora traga a sempre pungente questão sobre gêneros textuais/discursivos, acolhe nosso caso particular: um texto-fonte em português sobre um tema científico, produzido em dada situação comunicativa, por redatores especialistas, adaptado, na mesma língua, para um leitor específico.

Como a nossa TI dá-se em um mesmo gênero, o texto divulgação científica, dificulta-se o enquadramento. Entretanto, categorizações tendem a ser redutoras e, no geral, dão margem a sobreposições. Assim, caberia pensar o texto, em seu estatuto 'original', como uma norma linguística 'mais culta', e a simplificação como uma outra variante, norma - ou registro -, mais popular ou menos escolarizada. Embora se possa seguir a reflexão, ficamos, por hora, com a ideia da TI Intergenérica. Afinal, ela inclui "texto especializado" e “leitor leigo”, tópicos familiares aos estudos de Terminologia de perspectiva textual (CIAPUSCIO 2003; BouRIGAULT; SLOdZIAN [1999] 2004).

\subsection{Corpora envolvidos}

Lidamos com textos anexos a objetos junto a suas simplificações para alunos do final do Ensino Fundamental. Daí partimos para um corpus paralelo diferente do que se costuma encontrar em estudos de Tradução associados à Linguística de Corpus (doravante LC). Afinal, tais corpora costumam envolver línguas diferentes (VIANA; TAGNIN 2015).

Em LC, conforme Berber Sardinha (2004), um corpus é um acervo textual, criteriosamente constituído, para espelhar um estado de uso da língua. Em formato digital, é explorado com o apoio computacional. E, seguindo Zavaglia e Ferraresi (2006: 503-504), quanto à organização interna, dizemos que um corpus é paralelo quando possuir textos comparáveis - caso

TradTerm, São Paulo, v.37, n. 1, janeiro/2021, p. 30-63

Número Especial - Linguística de Corpus www.revistas.usp.br/tradterm 
de originais acompanhados da sua tradução. Será paralelo alinhado quando as traduções ficam posicionadas abaixo de cada linha do original.

Assim, nosso corpus, em construção, sendo paralelo, contém:

a) textos-fonte - originais em português produzidos por técnicos do Museu de Ciências e Tecnologia da Pontifícia Universidade Católica do RS (doravante MCT-PUCRS) - considerados por nós, em tese, complexos, dirigidos para o público em geral;

b) textos-alvo - diferentes versões, em português, por nós simplificadas, lexical e sintaticamente, destinadas para alunos do final do Ensino Fundamental de escolas públicas.

Nossa unidade de pareamento é o trecho, e não linhas ou frases. Além disso, a efetiva maior simplicidade dos textos depende, ainda, de testagens com leitores. Alguns testes, com originais e simplificações, já foram feitos com estudantes em visita ao MCT-PUCRS e também em suas salas de aula. Entretanto, a qualificação 'original potencialmente complexo' partiu de verificações diversas (TCACENCO 2019), em um universo inicial de 600 textos do MCT-PUCRS. Desse conjunto, retiramos 150 textos, 'exemplarmente' complexos, agora contrastados e alinhados.

Os textos da amostra têm, em média, 150 palavras. A descrição e análise dos originais, que subsidiam as reescritas simplificadas, baseiam-se em estudos que já lidaram com complexidade, simplificação e ATT. Entre esses: DuBay (2004), com reflexões históricas sobre a reescrita simplificada; Aluísio e Gasperin (2010), com corpora e ferramentas para simplificação em português; e, principalmente, Silva (2018) e Pasqualini (2018), com validações de estratégias de simplificação e um corpus de referência para vocabulário escrito simples.

Para a reformulação, além do apoio bibliográfico, procuramos ter em mente um todo do texto em sua funcionalidade, sem um foco restrito à sentença/frase ou à palavra. Assim, colocamo-nos na posição de pessoas que realizam diferentes transformações de reescrita, um processo em etapas, com apagamentos, alterações e inserções de elementos. Como analistas e críticos do nosso próprio texto, que inclui tentativas e erros, ponderamos sobre procedimentos, sem recorrer a algum dataset específico.

TradTerm, São Paulo, v.37, n. 1, janeiro/2021, p. 30-63

Número Especial - Linguística de Corpus www.revistas.usp.br/tradterm 


\subsection{Um exemplo para situar a TI}

No Quadro 1, temos um texto do corpus. Nele, vemos um original considerado potencialmente complexo para o público infanto-juvenil - parte da exposição "Evidências da Evolução", do MCT-PUCRS, de 2016. Nele apresenta-se a expedição de Darwin, começando por seu navio, o Beagle:

Quadro 1: Versão original.

O Beagle partiu de Plymouth, Inglaterra, no dia 27 de dezembro de 1931. A tripulação de 74 homens tinha como objetivo melhorar os mapas e proteger os interesses britânicos. O plano era realizar uma viagem de dois anos pela costa da América do Sul, mas acabou tornando-se uma jornada de circum-navegação que durou cinco anos: de 1831 a 1836. Darwin viajou como naturalista de bordo, para explorar e coletar espécimes.

Fonte: MCT-PUCRS (2016)

No Quadro 2, a sua primeira versão simplificada. Vale observar o aumento do texto.

Quadro 2: Versão simplificada 1.

O navio Beagle partiu da cidade de Plymouth, Inglaterra, no dia 27 de dezembro de 1931. As pessoas que estavam no navio eram 74 homens. Sua missão era melhorar os mapas e as descrições que havia naquela época sobre diferentes partes do mundo, o que ajudaria também a proteger os interesses comerciais do Reino Unido. O plano era fazer uma viagem de dois anos pela costa da América do Sul, mas a viagem acabou virando uma volta ao mundo de cinco anos: de 1831 a 1836. Darwin estava no navio como um naturalista, isto é, sua função era estudar a natureza, explorar lugares e recolher amostras de materiais e de seres vivos.

Fonte: os autores.

Como se nota, extrapola-se 'simples' explicação ou reformulação. Fosse isso, bastaria trocar poucas palavras, como 'circum-navegação', por um sinônimo ou paráfrase, em tese, mais fácil. Evidencia-se, assim, toda uma ponderação sobre 'lacunas' a preencher, sobre custos e benefícios de escolhas. A explicitação, como aumenta palavras, pode ser um complicador, mas também pode ajudar o leitor. Em face dessa ponderação, opta-se por uma dada escrita, por uma alternativa entre várias possíveis.

TradTerm, São Paulo, v.37, n. 1, janeiro/2021, p. 30-63

Número Especial - Linguística de Corpus www.revistas.usp.br/tradterm 
Como em críticas de traduções de um mesmo original, feitas por diferentes profissionais, pode-se dizer: 'eu teria feito de outro modo'. Nesse caso, com novas frases tão longas, teríamos algo a melhorar. Por isso, o que trazemos visa situar e ilustrar um processo e seus desafios.

Para as propostas de simplificação, que se sucedem, nosso pensamentoguia é identificar modos de favorecer a ATT (FINATTO; MOTTA 2019). Também tem sido importante consultar o CorPop (Pasqualini 2018), um corpus de referência para o que seria mais ou menos compreensível para um leitor com escolaridade limitada. No caso dos Quadros 1 e 2, itens como COLETAR e TRIPULAÇÃO, com ocorrências quase nulas no CorPop, poderiam ser difíceis para leitores com escolaridade limitada. Baseando-nos em dados de frequência desse corpus, optamos pela reescrita com RECOLHER, que tem 70 ocorrências, incluindo flexões, e PESSOAS DO NAVIO, com 890 ocorrência para PESSOA e 28 para NAVIO.

Essa reescrita também inclui estimar, previamente, por exemplo, a potencial dificuldade lexical para dado tipo de leitor. Tal estimativa pode ser realizada: a) via contato direto com os leitores visados; b) com dados sobre o seu perfil de compreensão de leitura; ou, c) pela combinação dessas duas alternativas.

Poder-se-ia, como no exemplo, aumentar o texto, repetir palavras, preencher lacunas que se suponha existir para a compreensão. Essas são estratégias de simplificação já testadas, com sucesso, em diferentes estudos (SILVA 2018). Ainda assim, nas diferentes escolhas, repercutem as concepções do redator-simplificador sobre o tipo de trabalho que está realizando, sobre o que ele deseja com a reescrita e sobre o quanto ele pode, ou não, interferir, a partir do texto-fonte.

Nesse particular, salientamos que, como na 'tradução normal', na simplificação, é preciso sopesar a autoria, as escolhas do original e as do texto de chegada. Em geral, na autoria do original, há um museólogo, um curador ou um especialista no assunto em foco. Assim, vale, para a TI, o mesmo que se pondera para a 'normal': os limites entre tradutor e autor, as (eternas) questões sobre 'fidelidade' e sobre o quanto se pode interferir. Nas diferentes formas da reescrita simplificada, feitas por diferentes pessoas, do

TradTerm, São Paulo, v.37, n. 1, janeiro/2021, p. 30-63

Número Especial - Linguística de Corpus www.revistas.usp.br/tradterm 
texto-fonte ao de chegada, vemos as subjetividades envolvidas. Em cada simplificação, há, também, uma autoria.

Concepções, propósitos e comportamentos de diferentes tradutoresadaptadores, tal como já foi estudado, por exemplo, na estilística da tradução, em Magalhães, Castro e Montenegro (2013) ou em Magalhães e Blauth (2015), poderiam ser identificados, em um corpus paralelo como o nosso. Esses estudos, entre outros, sobre estilística tradutória baseados em corpora, podem ser estendidos ao contraste entre originais e simplificações.

Por outro lado, em termos metodológicos, a problemática do alinhamento - sentencial ou outro - entre original e a versão simplificada, nesse tipo de corpus, também é um desafio. Isso vê-se nos quadros 1 e 2 . Afinal, os diferentes tipos de intervenções da reescrita tendem a dificultar a paralelização 1 a 1 .

Todavia, há alternativas para dinamizar o processo de alinhamento de traduções, que é bastante custoso. São úteis os alinhamentos automáticos de traduções em corpora paralelos tradicionais, via ferramentas de PLN (CASELI 2005; SCHREINER 2010 ou LeLLIS 2017) e também o alinhamento feito por ferramentas de LC. Ademais, em PLN, já podemos aproveitar trabalhos com alinhamento lexical e sentencial de originais e simplificações em português (CASELI ET AL. 2009), como também rankings de leitores sobre complexidadesimplicidade, confrontando-se avaliações feitas 'por máquina' e por pessoas.

No cenário da Linguística Aplicada em interface com o PLN, vale também registrar iniciativas para verificar níveis de complexidade ou inteligibilidade de materiais literários adaptados. Esses trabalhos, de diferentes modos, contrastam originais e adaptações. Um exemplo é o estudo de Rodrigues, Freitas e Quental (2013), com recursos computacionais, sobre a inteligibilidade de obras literárias adaptadas para adultos recémalfabetizados.

Sem maiores aprofundamentos sobre estudos em interface e corpora paralelizados já disponíveis, entrelaçamos, a seguir, em torno da TI, Linguística de Corpus (LC), tradução em corpora e estudos de Terminologia.

TradTerm, São Paulo, v.37, n. 1, janeiro/2021, p. 30-63 Número Especial - Linguística de Corpus www.revistas.usp.br/tradterm 


\subsection{LC, Terminologia e simplificação de textos}

A LC, como resume Tagnin (2015: 19), "é uma abordagem empírica para o estudo da língua, em suas diversas dimensões, como, por exemplo, no léxico e no discurso". E, conforme está na abertura da obra "Corpora e Tradução", de Viana e Tagnin (2015: 2), "a pesquisa da tradução, especialmente em corpora paralelos, à medida que nos possibilita buscar respostas, sempre nos traz novas e interessantes perguntas sobre processos e produtos tradutórios".

Por sua vez, a Terminologia, como ramo da Linguística Aplicada ${ }^{1}$, ao estudar os diferentes fenômenos verificados nos cenários da comunicação especializada, "é uma disciplina que possui o seu objeto primordial definido: o termo técnico-científico" (KRIEGER; FinatTo 2004: 20). Mas, além dos termos, toda uma ambiência textual também entra em consideração.

Em Terminologia, cada vez mais, lida-se com acervos textuais e práticas de discurso que podem estar sob a forma de corpora. Neles, há os termos, mas também toda uma série de outros elementos, igualmente significativos para a descrição e caracterização de um discurso específico e multifacetado, que terá diferentes apresentações. Com tal ampliação, a transformação dos textos do MCT-PUCRS, no todo de sua tessitura e das suas terminologias, também interessará à Terminologia. Em especial, à Terminologia de viés textual e comunicativo.

A seguir, tratamos das estratégias de equivalência em tradução propostas por Baker ([1992] 2018). A ideia é aproximá-las do nosso caso e do processo, em construção, da escrita de simplificações.

\section{Estratégias de equivalência em tradução}

Baker ([1992] 2018) analisou técnicas de equivalência de profissionais lidando com diferentes pares de línguas. Seus procedimentos foram examinados em vários níveis: palavra, frase, gramática, o todo do texto, nível pragmático e semiótico. Após descrevê-los, a autora examina as estratégias

\footnotetext{
1 A Terminologia também pode ser considerada como um ramo da Linguística teórica ou descritiva, enquanto a Terminografia seria vinculada à Linguística Aplicada.
}

TradTerm, São Paulo, v.37, n. 1, janeiro/2021, p. 30-63

Número Especial - Linguística de Corpus

www.revistas.usp.br/tradterm 
mais utilizadas.

Seu exame pode nos ajudar a entender modos de simplificação como tentativas de equivalência tradutória. Vejamos, a seguir, um resumo da sua classificação.

\subsection{Equivalência no nível da palavra}

Dada a não correspondência entre palavra e significado em muitos contextos envolvendo duas línguas diferentes, Baker ([1992] 2018) resgata a palavra como unidade referencial. Para tanto, recupera as contribuições da Semântica (CRUSE 1986) sobre tipos de significado, a saber: proposicional (baseado na relação entre a palavra ou o enunciado e a que eles se referem no mundo real, podendo ser classificado como verdadeiro ou falso); expressivo (de caráter avaliativo em que estão as atitudes e sentimentos do interlocutor, não podendo ser julgado verdadeiro ou falso); pressuposto (relacionado com as colocações) e evocado (resultante de questões dialetais e de registro). Baker argumenta que muitos problemas de imprecisão em traduções seriam atribuíveis ao significado proposicional. Daí, traz as estratégias mais comuns, citando o uso de:

a) palavra mais geral (hiperônimo).

b) palavra mais neutra / menos expressiva;

c) substituição cultural;

d) empréstimo ou empréstimo seguido de paráfrase explanatória;

e) paráfrase com o uso de uma palavra relacionada;

f) paráfrase com o uso de palavras não relacionadas;

g) omissão e

h) ilustração.

\subsection{Equivalência no nível acima da palavra}

Nesse nível, a autora situa as colocações. Argumenta que têm papel central, já que podem impor restrições à produção de significado por conta das palavras que são combinadas. Nesse plano, traz, como desafio, a tradução de expressões fixas e idiomáticas.

TradTerm, São Paulo, v.37, n. 1, janeiro/2021, p. 30-63

Número Especial - Linguística de Corpus

www.revistas.usp.br/tradterm 
Alguns dos problemas elencados por Baker quanto às colocações são: a) adesão extrema à estrutura da língua de partida; b) falha na compreensão do significado de uma colocação de uma língua de partida; c) tensão entre precisão e naturalidade; d) colocações que são específicas de uma cultura; e e) colocações marcadas no texto de partida.

Dentre as dificuldades da tradução dessas expressões, coloca: a) falta de equivalente para a expressão fixa e idiomática na língua de chegada; b) a expressão fixa e idiomática, na língua de partida, aparenta ter um equivalente na língua de chegada, mas difere no contexto de uso; c) uso de uma expressão fixa e idiomática na língua de partida tanto em sentido literal como idiomático, ao mesmo tempo e d) uso de idiomatismos no discurso escrito com contextos de ocorrência e de frequência de uso diferentes entre língua de partida e de chegada.

No nível das expressões, os recursos de equivalência mais empregados são usos de:

a) expressão idiomática de forma e significado semelhantes;

b) expressão idiomática de significado semelhante, mas forma diferente;

c) empréstimo da expressão idiomática a partir da língua de partida;

d) paráfrase;

e) tradução via omissão da parte lúdica da expressão idiomática em favor de seu sentido literal;

f) omissão da expressão idiomática; e,

g) introdução da idiomaticidade em outro ponto do texto para compensar ou sinalizar sua presença no discurso.

\subsection{Equivalência no nível textual}

Para Baker ([1992] 2018: 134), "o arranjo linear de elementos linguísticos desempenha um papel importante na organização das mensagens em um nível textual" (todas as traduções são de nossa autoria) ${ }^{2}$. Assim, falhas na sua disposição comprometeriam o que denomina "fluxo de informações".

\footnotetext{
2 "The linear arrangement of linguistic elements plays a role in organizing messages at text level."
}

TradTerm, São Paulo, v.37, n. 1, janeiro/2021, p. 30-63

Número Especial - Linguística de Corpus

www.revistas.usp.br/tradterm 
Dado que uma tradução deve ter um fluxo regular de informações para poder ser facilmente acompanhado pelo leitor, importa que o tradutor tenha consciência de que determinada formulação textual pode impactar a compreensão.

Para ilustrar esses aspectos, Baker resgata a perspectiva do funcionamento textual de Halliday (1985). Nela, a interação entre as frases em um texto é descrita através das relações entre tema e rema. O tema, geralmente em posição inicial no enunciado, é o tópico. O rema, por sua vez, corresponde àquilo que se diz sobre o tópico.

Em perspectiva mais orientada ao ouvinte, Baker traz o que Halliday (1985) denominou estrutura da informação. O texto, nessa visão, é interface entre o que já foi dito e o que ainda não foi: o dado e o novo em sucessão. Com essa perspectiva, salienta que "a tradução entre línguas com prioridades diferentes e distintos tipos de restrições sintáticas exige um alto grau de flexibilidade nos padrões de fluxo da informação (BAKER [1992] 2018: 179)"3. As estratégias para enfrentar dessa exigência, conforme a autora verificou, são:

a) mudança de voz (de ativa para passiva e vice-versa);

b) uso de um verbo diferente;

c) nominalização e

d) extraposição.

Usar tais estratégias é lidar com o texto-fonte e alvo de maneira que as informações apresentadas façam sentido para o leitor. Assim, entram em cena não somente elementos de coesão textual, como referenciação, substituição, elipses, conjunções, além do próprio léxico, mas também elementos pragmáticos, como coerência e implicaturas.

Com relação às questões de ordem pragmática, Baker argumenta que

[...] a coerência é uma noção bastante problemática e fugidia por conta da diversidade de fatores linguísticos e não linguísticos que podem ter alguma relevância sobre ela, e os diferentes graus de importância que um fator pode assumir em dado contexto... (BAKER [1992] 2018: 267) .

\footnotetext{
3 "Translating between languages with different priorities and different types of syntactic restrictions necessarily involves a great deal of skewing of patterns of information flow."

4 "Coherence is a very problematic and elusive notion because of the diversity of factors. Linguistic and non-linguistic, that can affect it and the varying degrees of importance a particular factor can assume in a given context."
}

TradTerm, São Paulo, v.37, n. 1, janeiro/2021, p. 30-63

Número Especial - Linguística de Corpus www.revistas.usp.br/tradterm 
Entretanto, um texto pode não fazer nenhum sentido para o leitordestinatário. Ao que acrescenta que:

As maiores dificuldades aparentam estar relacionadas com a habilidade de se avaliar o nível de conhecimento do leitor do texto de partida e suas crenças acerca de vários aspectos do mundo e como alcançar equilíbrio entre, por um lado, ir ao encontro das suas expectativas, mas, por outro, manter o interesse na atividade comunicativa através da oferta de conhecimentos novos ou alternativos ([1992] 2018, p. 268) $)^{5} \ldots$

Pontos críticos que o profissional deve atentar, conforme a autora, incluem a) o uso de repetições, cuja aceitabilidade pode variar de língua para língua; b) a relação do texto com o contexto de ocorrência, caso das dimensões de um terreno em pés quadrados que faz sentido para um brasileiro; c) a ordem de uma sequência narrativa tende a ser temporal ordens diferentes podem causar confusão; d) as datas - no Brasil, a ordem usual é dia, mês e ano, com ordem diferente poder-se-ia tomar o número do mês pelo número do dia e vice-versa; e) títulos e formas de tratamento - em português, frente ao inglês e russo, não usamos o título (Sr., Sra. ou Srta.) antes de sobrenomes, mas, sim, antes dos primeiros nomes.

\subsection{Equivalência semiótica}

Quando o texto-fonte traz elementos como imagens, gestos, linguagem corporal e cores (BAKER 2018; VAN LEEUWEN 2005), é preciso cuidado redobrado. Como culturas distintas podem interpretar signos não verbais de modos diferentes, é vital não deixar lacunas, ou o destinatário ficará imerso em dúvidas. Ademais, muitas vezes, o verbal e o visual funcionam lado a lado. Ao que Baker acrescenta que ambos, “complementam-se de várias maneiras, as quais criam tanto dificuldades quanto oportunidades para o tradutor (2018:

\footnotetext{
5 "The main difficulties seem to be concerned with the ability to assess the target readers' range of knowledge and assumptions about various aspects of the world and to strike a reasonable balance between, on the one hand, fulfilling their expectations and, on the other hand, maintaining their interest in the communication by offering them new or alternative insights."
}

TradTerm, São Paulo, v.37, n. 1, janeiro/2021, p. 30-63

Número Especial - Linguística de Corpus www.revistas.usp.br/tradterm 
293) $)^{6} . "$

As estratégias para lidar com as dificuldades nesse plano podem ser:

a) fortalecimento da coesão verbo-visual;

b) minimização de discrepâncias relacionadas ao insumo visual e verbal;

c) substituição de pistas verbo-visuais;

d) compensação; e,

e) sacrifício ou invalidação da coesão verbo-visual.

\subsection{Para resumir e prosseguir}

$\mathrm{Na}$ equivalência no nível da palavra e acima dela, o léxico tem papel fundamental. Todavia, não é o único ponto a considerar. As estruturas gramaticais - materializadas via aspectos morfológicos e sintáticos - têm papel igualmente importante na transformação dos nossos pensamentos em palavras e, por conseguinte, na veiculação de nossas experiências via texto.

Fatores gramaticais e textuais, como número, gênero, pessoa, tempo e aspecto verbais, voz (ativa ou passiva), ordem de palavras, assim como, no português, o grau, não podem ser desprezados. Afinal, indicam os níveis de diversidade das gramáticas e dos modos de significação das línguas envolvidas, o que poderíamos tentar transpor para o processo de simplificação.

Assim, a seguir, situamos a identificação de como essas estratégias ocorrem no nosso corpus.

\section{Corpus e métodos}

Nosso corpus contém a diversidade de temas e de tipos de exposições de 600 textos do MCT-PUCRS. Entre os temas, há tópicos de Matemática, Física, Botânica, Esportes, Zoologia, Geografia, Geologia, entre outros. Para uma amostra pareada, com 150 textos, consideramos a potencial concretude da informação posta no texto, escolhendo os que tivessem maior complementaridade com o objeto a que se referem.

\footnotetext{
6 "The two channels, together with a multiplicity of semiotic resources employed by them, complement each other in various ways that create both difficulties and possibilities for the translator."
}

TradTerm, São Paulo, v.37, n. 1, janeiro/2021, p. 30-63

Número Especial - Linguística de Corpus

www.revistas.usp.br/tradterm 
Alguns textos são explicativos, outros descritivos e uma grande maioria incita à ação, pois acompanham experimentos interativos. No Quadro 3, um exemplo de texto completo, explicativo, com 107 palavras, da exposição "Marcas da Evolução". Não há remissões diretas ao objeto, embora o texto funcione junto a uma réplica de um animal:

Quadro 3: Texto da exposição Marcas da Evolução

TARTARUGAS-GIGANTES-DE-GALÁPAGOS
Chelonoidis nigra
São encontradas apenas no arquipélago de Galápagos, no Equador. Podem
atingir mais de $1,80 \mathrm{~m}$ de comprimento e chegar a $400 \mathrm{~kg}$, com uma
expectativa de vida de cerca de 150 anos.
A população atual dessa espécie está estimada em 20 mil indivíduos,
aproximadamente, muito longe dos 250 mil que ali viviam antes do início
da colonização espanhola. É provável que, nos dias de hoje, o arquipélago
abrigue 11 variedades (subespécies) da tartaruga-gigante-de-Galápagos,
cada uma com características específicas. Sua diversidade morfológica,
bem como a de outros animais que habitam Galápagos, foi um dos pilares
da teoria sobre a evolução das espécies elaborada por Darwin.

Fonte: MCT-PUCRS (2016)

Nossa amostra de 150 textos foi processada, no seu todo, com o software AntConc versão 3.5.8 (ANTHONY 2020). Assim, nossas contagens básicas mais gerais são: a) número total de palavras (tokens): 23.079 itens; b) palavras diferentes (types): 4.678 formas; c) variedade média do vocabulário (TTR ou escore de riqueza lexical): cerca de 20,2\%; d) média de palavras por texto: 154.

As palavras mais frequentes são: DE, com 1.083 usos, A com 948 ocorrências, 0 com 806 ocorrências. 0 item QUE está na posição número 5 , com 551 ocorrências. A primeira palavra lexical mais usada, por ordem de frequência, é VIDA, com 91 ocorrências, estando na posição 31 da lista (wordlist). Essas contagens, no todo e em cada texto da amostra, foram consideradas no contraste entre originais e simplificações.

Conforme reiterado, esse corpus está em construção. A reescrita, em etapas, usa indicativos de Silva (2018) e de testes preliminares de compreensão de leitura com estudantes, com idades entre 10 e 14 anos, em visita ao MCT-PUCRS. Em uma sucessão de tarefas, nosso método consiste em:

a) revisar a correspondência entre o original e uma ou mais versões

TradTerm, São Paulo, v.37, n. 1, janeiro/2021, p. 30-63 Número Especial - Linguística de Corpus www.revistas.usp.br/tradterm 
simplificadas suas, identificando seus segmentos e corrigindo o que for necessário, conforme o leitor visado, indicações da bibliografia e consulta ao CorPop;

b) a partir da etapa anterior, fixar uma dupla com o original e sua versão de simplificação consolidada final;

c) verificar empregos de alguma das estratégias de equivalência de Baker (2018) ao longo dos segmentos dos textos simplificados;

d) apontar as principais alterações entre cada dupla de textos em termos de: estratégia(s) de equivalência empregada(s), quantidades e distribuição de palavras, tratamento de terminologias, listagens e contagens de itens mais e menos frequentes, riqueza lexical e Índice Flesch (a seguir detalhado). Nessa etapa, usamos o sistema Coh-Metrix Dementia (CUNHA 2015), um analisador automático de características textuais, que aponta possíveis elementos de complexidade de um dado texto;

e) parear e alinhar, em modo final, os segmentos do texto-fonte com os do texto-alvo, em suas diferentes versões, com comentários e descrições por blocos;

f) sistematizar características da redação simplificada para um guia com sugestões para profissionais envolvidos com essa atividade.

\section{Verificação de estratégias e discussão}

Para ilustrar, em especial a busca de modos de equivalência, trazemos um texto completo anexo a um equipamento do MCT-PUCRS intitulado "Giroscópio Humano". Esse giroscópio, como se explica ao visitante, é uma réplica de equipamento usado na NASA. A seguir, no Quadro 4, o texto original:

TradTerm, São Paulo, v.37, n. 1, janeiro/2021, p. 30-63

Número Especial - Linguística de Corpus www.revistas.usp.br/tradterm 
Quadro 4: Versão original do texto Giroscópio Humano

Ficando para trás na corrida espacial, os Estados Unidos contra-atacaram com o projeto Mercury, entre 1958 e 1963. A bordo da espaçonave MercuryRedstone 3, Alan Shepard foi o primeiro norte-americano a chegar ao espaço, em maio de 1961, apenas um mês após o famoso voo do russo Yuri Gagarin.Com formato cônico e espaço para apenas um tripulante, a MercuryRedstone 3 realizou um voo de $486 \mathrm{Km} \mathrm{em}$ pouco mais de 15 minutos, alcançando a velocidade de $8.340 \mathrm{~km} / \mathrm{h}$.

Mesmo sem ter ultrapassado a União Soviética na Corrida Espacial, o Projeto Mercury estabeleceu as condições para que, alguns anos depois, o homem chegasse a Lua. Como parte do treinamento da equipe do Projeto Mercury, a NASA criou um equipamento chamado de MASTIF (Multiple Axis Space Test Inertia Facility ou Instalação de Eixos Múltiplos para Teste de Inércia no Espaço). Com ele, os astronautas preparavam-se para se movimentar em um ambiente sem a ação da força gravitacional terrestre. O MASTIF simulava manobras semelhantes a cambalhotas, que podem ser encontradas em voos espaciais. Seus três aros de alumínio tubular giravam separadamente ou de forma combinada, simulando os movimentos de inclinação, rotação e guinada que seriam encontrados quando a Mercury estivesse no espaço.

O experimento Giroscópio Humano é uma versão simplificada do MASTIF. Faça um teste e sinta-se como um astronauta no espaço. Com a Apollo XI, o sonho de chegar à Lua finalmente se torna realidade para a NASA.

Fonte: MCT-PUCRS (2016)

Esse texto, aqui sem formatação, tem 241 palavras (tokens). Submetido ao sistema Coh-Metrix Dementia (CUNHA 2015), mostra um Índice Flesch (IF) em torno de 34,5 pontos. Isso o enquadra como um texto potencialmente bastante difícil.

O IF é uma escala para estimar complexidade que vai de 0 a 100 . Foi testado, por exemplo, nos trabalhos de Silva (2018) e Pasqualini (2018), e em vários estudos de PLN já citados. O valor de 100 pontos corresponde a um máximo de facilidade. Entre zero e 25 pontos, teríamos os textos muito difíceis, adequados para leitores de instrução universitária. De 25 a 50 pontos, os textos considerados mediamente difíceis, compatíveis com leitores com Ensino Médio.

No Quadro 5, vemos uma tentativa de simplificação. Sua complexidade, pelo IF, no mesmo sistema, é estimada em 41,6 pontos. Tal escore o coloca, $a$ priori, como difícil para alunos do Ensino Fundamental. Para leitores desse nível, nessa escala, seria preciso um texto com IF entre 50 e 75 pontos, o que

TradTerm, São Paulo, v.37, n. 1, janeiro/2021, p. 30-63 Número Especial - Linguística de Corpus www.revistas.usp.br/tradterm 
implicaria mais ações, como reduzir o tamanho das frases, por exemplo.

Quadro 5: Versão simplificada 1 do texto Giroscópio Humano

Depois de sair perdendo na Corrida Espacial, uma intensa competição entre Estados Unidos e União Soviética pela exploração do espaço, os americanos contra-atacaram com o projeto Mercury, entre 1958 e 1963. A bordo da espaçonave Mercury-Redstone 3, Alan Shepard foi o primeiro norte-americano a chegar ao espaço, em maio de 1961, apenas um mês após o famoso voo do russo Yuri Gagarin. A Mercury-Redstone 3 tinha o formato de um cone e espaço para apenas um tripulante. Seu voo de $486 \mathrm{Km}$, em pouco mais de 15 minutos, chegou à velocidade de $8.340 \mathrm{~km} / \mathrm{h}$.

Mesmo sem ter ultrapassado a União Soviética na Corrida Espacial, o Projeto Mercury permitiu que, alguns anos depois, o homem chegasse à Lua. Para treinar a equipe do Projeto Mercury, a NASA criou um equipamento chamado de MASTIF (Multiple Axis Space Test Inertia Facility ou "Instalação de Eixos Múltiplos para Teste de Inércia no Espaço"). Com ele, os astronautas se preparavam para se movimentar em um ambiente sem a ação da força da gravidade que existe na Terra. O MASTIF simulava manobras parecidas com cambalhotas, bem semelhantes às que os astronautas fazem em voos espaciais. Seus três aros de alumínio em formato de tubo giravam separadamente ou ao mesmo tempo. Ali simulavam movimentos de inclinação, rotação e guinada iguais aos que os tripulantes executariam quando a Mercury estivesse no espaço.

O experimento Giroscópio Humano é uma versão simplificada do MASTIF. A partir desse conhecimento, com a Apollo XI, em 1969, o sonho de chegar à Lua finalmente se tornou uma realidade para a NASA. Faça um teste e sinta-se como um astronauta no espaço.

Fonte: Os autores

Esses textos sobre o giroscópio, original e simplificação, ilustrarão nossa verificação. Assim, esta seção segue em quatro partes, que separam diferentes níveis, da palavra ao texto. Trazemos uma série de quadros com segmentos pareados, por tipos, com itens em equivalência em negrito e comentários. Alguma sobreposição entre os níveis foi inevitável, sendo apontada. Como a reescrita é uma primeira versão, cabem, naturalmente, reparos e críticas. Isso, presumimos, não invalida sua utilidade.

TradTerm, São Paulo, v.37, n. 1, janeiro/2021, p. 30-63

Número Especial - Linguística de Corpus www.revistas.usp.br/tradterm 


\subsection{Nível da palavra}

Quadro 6: Tradução por paráfrase com uso de palavra relacionada

\begin{tabular}{|l|l|}
\hline \multicolumn{1}{|c|}{ TEXTO-FONTE } & \multicolumn{1}{|c|}{ TEXTO-ALVO } \\
\hline Ficando para trás na corrida espacial, & Depois de sair perdendo na Corrida \\
os Estados Unidos contra-atacaram & Espacial, uma intensa competição \\
com o projeto Mercury, entre 1958 e entre Estados Unidos e União Soviética \\
1963. & $\begin{array}{l}\text { pela exploração do espaço, os } \\
\text { americanos contra-atacaram com o } \\
\text { projeto Mercury, entre 1958 e 1963. }\end{array}$ \\
\hline
\end{tabular}

Fonte: Os autores

Conforme Baker ([1992] 2018), a estratégia de tradução por paráfrase com uso de palavra relacionada tende a ser usada quando um conceito expresso em uma língua de partida está lexicalizado em uma língua de chegada, mas de forma diferente. No português, tanto Estados Unidos como americanos são unidades lexicalizadas. Mas, pela intervenção com paráfrase explicativa, em que utilizamos Estados Unidos, optamos por não repetir o país e usar uma palavra relacionada, destacando pessoas ou 'um time' em ação. Entre Estados Unidos e americanos, a equivalência por paráfrase comporta uma troca de classe gramatical do item traduzido e uma equivalência entre ambos.

No exemplo, no Quadro 7, há também equivalência por paráfrase com uso de palavra relacionada. No entanto, com procedimentos diferentes.

Quadro 7: Tradução por paráfrase com uso de palavra relacionada

\begin{tabular}{|c|c|}
\hline TEXTO-FONTE & TEXTO-ALVO \\
\hline $\begin{array}{l}\text { Com formato cônico e espaço para } \\
\text { apenas um tripulante, a Mercury- } \\
\text { Redstone } 3 \text { realizou um voo de } 486 \mathrm{Km} \\
\text { em pouco mais de } 15 \text { minutos, } \\
\text { alcançando a velocidade de } 8.340 \\
\mathrm{~km} / \mathrm{h} \text {. }\end{array}$ & $\begin{array}{l}\text { A Mercury-Redstone } 3 \text { tinha o formato } \\
\text { de um cone e espaço para apenas um } \\
\text { tripulante. Seu voo de } 486 \mathrm{Km} \text {, em } \\
\text { pouco mais de } 15 \text { minutos, chegou à } \\
\text { velocidade de } 8.340 \mathrm{~km} / \mathrm{h} \text {. }\end{array}$ \\
\hline
\end{tabular}

Fonte: Os autores

No texto-alvo, além de duas frases para uma frase do original, temos uma locução nominal - o formato de um cone. Essa escolha baseia-se em Silva 
(2018), que estudou como adjetivos podem ser complicadores.

O mesmo vemos noutro segmento do texto, com tubular traduzido por em formato de tubo. Tanto cônico quanto tubular, no CorPop (PASQUALINI 2018), têm zero ocorrência. No Corpus Brasileiro (BERBER SARDINHA 2009), um acervo gigantesco frente ao CorPop, há apenas 1.343 ocorrências para tubular, e a maioria provém de textos técnicos (bulas, manuais, catálogos). Assim, o CorPop subsidia a troca de alcançar por chegar: nele, há 13 ocorrências para alcançar (no infinitivo) frente a 179 para chegar. Essa proporção segue nas formas flexionadas desses dois verbos.

Usar duas frases no lugar de uma frase longa é sempre mais aconselhável, mas o aposto antes de chegou pode ser um complicador.

\subsection{Equivalência em nível acima da palavra}

Vejamos agora a equivalência para fraseologismos, expressões fixas ou idiomáticas e colocações. Esses são grupos complexos, podendo-se discutir seus tipos e fronteiras.

Sem entrar em discussões, serão tratados aqui, grosso modo, como "blocos de palavras pré-fabricados, memorizados e prontos para o uso, que vêm em auxílio dos falantes nas interações comunicativas" (TERMIGNONI 2015: 221). Para mais desse tema, em Tradução e Lexicografia, recomendamos Termignoni (2015). Dito isso, vamos a um exemplo:

Quadro 8: Blocos: significado semelhante e forma diferente

\begin{tabular}{|l|l|}
\hline \multicolumn{1}{|c|}{ TEXTO DE PARTIDA } & \multicolumn{1}{|c|}{ TEXTO DE CHEGADA } \\
\hline $\begin{array}{l}\text { Ficando para trás na corrida espacial, os } \\
\text { Estados Unidos contra-atacaram com o } \\
\text { projeto Mercury, entre } 1958 \text { e } 1963 .\end{array}$ & $\begin{array}{l}\text { Depois de sair perdendo na Corrida } \\
\text { os americanos contra-atacaram com o } \\
\text { projeto Mercury, entre 1958 e } 1963 .\end{array}$ \\
\hline
\end{tabular}

Fonte: Os autores

Tanto ficando para trás como sair perdendo podem ser considerados fraseologismos. Neles, há uma ação-processo em que algo ou alguém começa em desvantagem em um deslocamento ou disputa. Como relação lógica, trata-

TradTerm, São Paulo, v.37, n. 1, janeiro/2021, p. 30-63

Número Especial - Linguística de Corpus www.revistas.usp.br/tradterm 
se de uma desvantagem que, na continuidade do processo, pode ou não ser revertida.

O bloco ficando para trás poderia ser facilmente entendível pelo público em geral. Mas, para o leitor infanto-juvenil, poderia haver dúvidas sobre 'onde' fica 'trás' e 'atrás de quem' se estaria. Assim, optamos pela expressão: sair perdendo. Outra opção seria 'começar perdendo'. Nesse caso, ao se 'traduzir' uma expressão, é importante não esquecer que o repertório e o conhecimento maior ou menor desses blocos de sentido depende da experiência do leitor-destinatário.

No mesmo segmento, já no nível do texto, temos o recurso da paráfrase explanatória, quando se explica, via aposto, 'Corrida Espacial'. Estudos de Terminologia, como os de Ciapuscio (2003), apontam a larga utilização desse recurso na divulgação científica de jornais. Silva (2018) também tratou dessa estratégia, atestando sua eficácia em textos sobre Saúde, embora sempre com o custo do acréscimo de palavras.

A seguir, nos quadros de 9 a 11, vemos alguns exemplos, entre outros presentes no texto, para a tradução por paráfrase no nível acima da palavra. No nosso caso, essa estratégia envolve lidar com locuções nominais, adjetivas, adverbiais ou verbais, estando elas no texto de partida ou sendo resultado no texto de chegada. Pela observação desses pares, colocados em correspondência de sentido, há mais aproximações entre simplificação e tradução.

Quadro 9: Bloco - expansão com paráfrase

\begin{tabular}{|l|l|}
\hline \multicolumn{1}{|c|}{ TEXTO-FONTE } & \multicolumn{1}{|c|}{ TEXTO-ALVO } \\
\hline $\begin{array}{l}\text { Com ele, os astronautas preparavam-se } \\
\text { para se movimentar em um ambiente } \\
\text { sem a ação da força gravitacional } \\
\text { terrestre. }\end{array}$ & $\begin{array}{l}\text { Com astronautas preparavam-se } \\
\text { para movimentar em um ambiente } \\
\text { sem ação da força da gravidade que } \\
\text { existe na Terra. }\end{array}$ \\
\hline
\end{tabular}

Fonte: Os autores

Tanto força gravitacional terrestre quanto força da gravidade que existe na Terra são formas lexicalizadas. Para o nosso leitor, optamos por 
transformar um adjetivo - ou no caso dois - em uma locução nominal. Assim, a equivalência de tradução por paráfrase materializa-se pela transformação de adjetivos em locuções nominais.

A seguir, ao contrário do caso anterior, com uma locução nominal na simplificação, uma locução verbal é parafraseada por um verbo. O uso do aposto, novamente, é discutível. No Quadro 11, uma locução adverbial substitui outra locução adverbial.

Quadro 10: Bloco - paráfrase via condensação

\begin{tabular}{|c|c|}
\hline TEXTO-FONTE & TEXTO-ALVO \\
\hline $\begin{array}{l}\text { Mesmo sem ter ultrapassado a União } \\
\text { Soviética na Corrida Espacial, o Projeto } \\
\text { Mercury estabeleceu as condições para } \\
\text { que, alguns anos depois, o homem } \\
\text { chegasse à Lua. }\end{array}$ & $\begin{array}{l}\text { Mesmo sem ter ultrapassado a União } \\
\text { Soviética na Corrida Espacial, o Projeto } \\
\text { Mercury permitiu que, alguns anos } \\
\text { depois, o homem chegasse à Lua. }\end{array}$ \\
\hline
\end{tabular}

Fonte: Os autores

Quadro 11: bloco - paráfrase com estrutura semelhante

\begin{tabular}{|l|l|}
\hline \multicolumn{1}{|c|}{ TEXTO-FONTE } & \multicolumn{1}{|c|}{ TEXTO-ALVO } \\
\hline $\begin{array}{l}\text { Seus três aros de alumínio tubular } \\
\text { giravam separadamente ou de forma } \\
\text { combinada,... }\end{array}$ & $\begin{array}{l}\text { Seus três aros de alumínio em formato } \\
\text { de tubo giravam separadamente ou ao } \\
\text { mesmo tempo. }\end{array}$ \\
\hline
\end{tabular}

Fonte: os autores

\subsection{Equivalências no nível do texto}

O nível do texto comporta uma série de recursos e de estratégias de tradução. Conforme Baker ([1992] 2018), esses procedimentos de equivalência materializam-se da frase até segmentos maiores. Destacamos alguns exemplos a seguir.

a) Mudança de voz: dois recursos de mudança de voz (de ativa para passiva e vice-versa):

TradTerm, São Paulo, v.37, n. 1, janeiro/2021, p. 30-63

Número Especial - Linguística de Corpus www.revistas.usp.br/tradterm 
Quadro 12: Mudança de voz - dois casos

\begin{tabular}{|c|c|}
\hline TEXTO-FONTE & TEXTO-ALVO \\
\hline $\begin{array}{l}\text { 1) O MASTIF simulava manobras } \\
\text { semelhantes a cambalhotas, que podem } \\
\text { ser encontradas em voos espaciais }\end{array}$ & $\begin{array}{l}\text { 1) O MASTIF simulava manobras } \\
\text { parecidas com cambalhotas, bem } \\
\text { semelhantes às que os astronautas } \\
\text { fazem em voos espaciais }\end{array}$ \\
\hline $\begin{array}{l}\text { 2) (...) os movimentos de inclinação, } \\
\text { rotação e guinada que seriam } \\
\text { encontrados quando a Mercury estivesse } \\
\text { no espaço }\end{array}$ & $\begin{array}{l}\text { 2) (...) os movimentos de inclinação, } \\
\text { rotação e guinada iguais aos que os } \\
\text { tripulantes executariam quando a } \\
\text { Mercury estivesse no espaço. }\end{array}$ \\
\hline
\end{tabular}

Fonte: Os autores

Esse recurso é amplamente utilizado em vários discursos e gêneros textuais como modo de distanciamento entre o sujeito e a ação. Examinado e testado como elemento de complexidade em Silva (2018), esse distanciamento poder ser um complicador. Assim, a opção foi inserir um sujeito - astronautas - e um verbo - fazer - para elucidar o objeto cambalhotas. 0 mesmo fizemos com o uso do sujeito - tripulantes - como executores dos movimentos inclinação, rotação e guinada.

b) Extraposição: o que gera, grosso modo, um texto de chegada com ordem diferente do texto de partida. 0 quadro 14 traz a alteração de posição do tópico (a nave Mercury-Redstone) e a quebra de frases como um tipo de extraposição.

Quadro 13: extraposição e quebra de frase

\begin{tabular}{|c|c|}
\hline TEXTO-FONTE & TEXTO-ALVO \\
\hline $\begin{array}{l}\text { Com formato cônico e espaço para } \\
\text { apenas um tripulante, a Mercury- } \\
\text { Redstone } 3 \text { realizou um voo de } 486 \mathrm{Km} \\
\text { em pouco mais de } 15 \text { minutos, } \\
\text { alcançando a velocidade de } 8.340 \mathrm{~km} / \mathrm{h}\end{array}$ & $\begin{array}{l}\text { A Mercury-Redstone } 3 \text { tinha o formato } \\
\text { de um cone e espaço para apenas um } \\
\text { tripulante. Seu voo de } 486 \mathrm{Km} \text { em pouco } \\
\text { mais de } 15 \text { minutos alcançou a } \\
\text { velocidade de } 8.340 \mathrm{~km} / \mathrm{h} \text {. }\end{array}$ \\
\hline
\end{tabular}

Fonte: os autores

TradTerm, São Paulo, v.37, n. 1, janeiro/2021, p. 30-63

Número Especial - Linguística de Corpus www.revistas.usp.br/tradterm 


\subsection{Equivalência semiótica e outros recursos}

Neste tipo de equivalência, conforme Baker ([1992] 2018), palavras ou segmentos maiores associam-se a imagens ou objetos. A associação pode ser tanto no sentido do texto para o objeto quanto de modo inverso. Junto aos objetos expostos no MCT-PUCRS, estão os diferentes textos do nosso corpus. Daí ser importante observar essa vinculação de originais a simplificações.

A Figura 1, a seguir, contextualiza a potencial sincronia entre texto e objeto. Nela vemos o giroscópio em uso por uma pessoa no museu: o elemento e a situação associados ao texto.

Figura 1: Giroscópio Humano

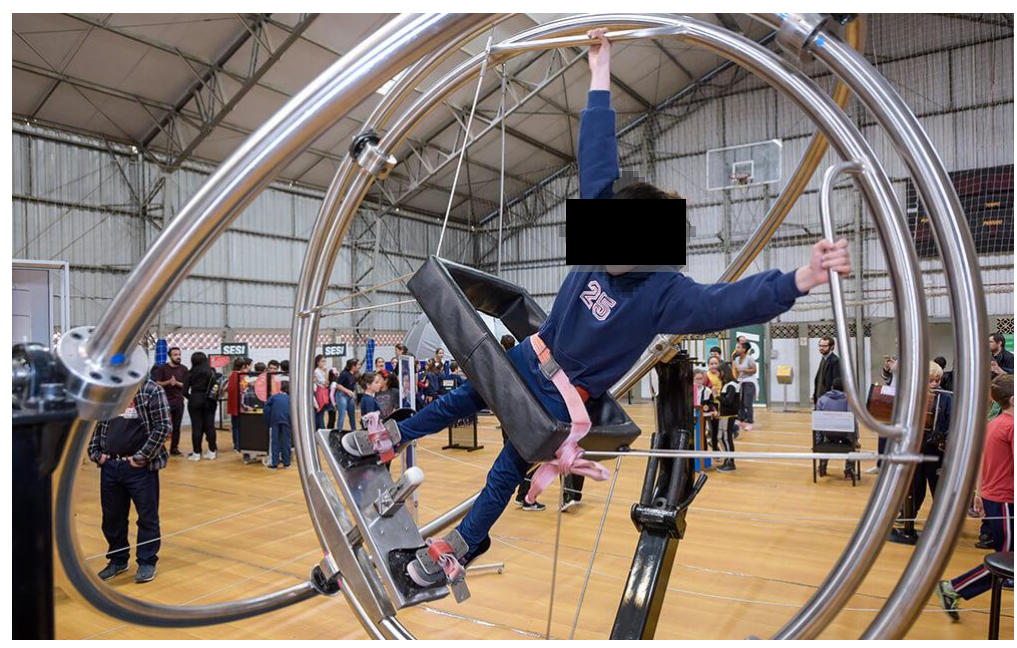

Fonte: MCT-PUCRS (http://www.pucrs.br/mct/museuitinerante/\#gallery-4). Acesso em: 28 mar 2020.

Tomando a equivalência apenas no nível da palavra, o objeto 'giroscópio' poderia ser considerado uma tradução 'concreta' do termo MASTIF, usado na simplificação e no texto-fonte. $O$ fato de haver um texto e um objeto para ilustrá-lo - ou vice-versa - colocaria ambos na categoria de tradução por ilustração.

0 experimento/objeto poderia ser considerado algo 'traduzido' ou representado na forma do texto escrito, uma vez que ele o situa, historicamente, e o descreve. Além disso, o texto deve motivar o leitor a experimentar o objeto, especialmente em "Faça um teste e sinta-se como um astronauta no espaço". Contudo, o giroscópio concreto, per se, não inclui uma 
descrição para o item MASTIF, nem seu histórico ou funcionalidade. 0 equipamento, no todo de uma aprendizagem que se pretende proporcionar, não é um recurso autossuficiente. Isto é, o leitor, de algum modo, 'precisa' do texto escrito - que pode ser apresentado oralmente por um monitor ou guia - para que o objetivo da aprendizagem seja completado.

Daí, pode ser lícito atribuir a essa relação o nome de complementação semiótica. Entre original e simplificação, veríamos, assim, a tradução de uma tradução, como camadas em torno de um núcleo que é o objeto concreto. Mas, também, pode-se pensar que esteja tudo condicionado, inclusive a constituição do objeto, por um dado propósito da aprendizagem. Vejamos, a propósito, um outro exemplo:

Quadro 14: Texto e objeto em relação a outros recursos

\begin{tabular}{|l|l|}
\hline \multicolumn{1}{|c|}{ TEXTO-FONTE } & \multicolumn{1}{|c|}{ TEXTO-ALVO } \\
\hline $\begin{array}{l}\text { Seus três aros de alumínio tubular } \\
\text { giravam separadamente ou de forma } \\
\text { combinada, simulando os movimentos } \\
\text { de inclinação, rotação e guinada que } \\
\text { seriam encontrados quando a Mercury } \\
\text { estivesse no espaço. }\end{array}$ & $\begin{array}{l}\text { Se tubo giravam separadamente ou ao } \\
\text { mesmo tempor ali simulavam } \\
\text { movimado de inclinação, rotação e } \\
\text { guinada aos que os tripulantes } \\
\text { executariam quando a Mercury estivesse } \\
\text { no espaço. }\end{array}$ \\
\hline
\end{tabular}

Fonte: Os autores

Os segmentos descritivos: (texto-fonte) "Seus três aros de alumínio tubular giravam separadamente ou ao mesmo tempo" e (texto-alvo) "Seus três aros de alumínio em formato de tubo giravam separadamente ou de forma combinada" referenciam o objeto original criado pela NASA, mas também apontam para o objeto que está na frente do leitor, tal como o dêitico Ali. No mesmo trecho alinhado, seguindo Silva (2018), dividimos uma frase em duas pensando em aumentar a fluidez do texto, aspecto comentado por Baker ([1992] 2018).

Fechando esta seção, vejamos a última parte do texto:

TradTerm, São Paulo, v.37, n. 1, janeiro/2021, p. 30-63

Número Especial - Linguística de Corpus www.revistas.usp.br/tradterm 
Quadro 16: Extraposição com paráfrase

\begin{tabular}{|l|l|}
\hline \multicolumn{1}{|c|}{ TEXTO-FONTE } & \multicolumn{1}{|c|}{ TEXTO-ALVO } \\
\hline $\begin{array}{l}\text { O experimento Giroscópio Humano é } \\
\text { uma versão simplificada do MASTIF. }\end{array}$ & $\begin{array}{l}\text { O experimento Giroscópio Humano é } \\
\text { uma versão simplificada do MASTIF. A } \\
\text { Faça um teste e sinta-se como um } \\
\text { astronauta no espaço. Com a Apollo XI, } \\
\begin{array}{l}\text { o sonho de chegar à Lua finalmente se desse conhecimento, com a a } \\
\text { torna realidade para a NASA. }\end{array}\end{array}$ \\
$\begin{array}{l}\text { Apollo XI, em 1969, o sonho de chegar à } \\
\text { Lua finalmente se tornou uma realidade } \\
\text { para a NASA. Faça um teste e sinta-se } \\
\text { como um astronauta no espaço. }\end{array}$ \\
\hline
\end{tabular}

Fonte: Os autores

Aqui, uma nova informação - Apolo XI -, surge, pela primeira vez, no fecho do original, o que é um complicador. Na simplificação, além do deslocamento, resgata-se uma relação de causa-efeito e inclui-se uma data, pois o leitor pode não ter tal referência. O aposto (com a Apollo XI), novamente, pode ser considerado um elemento complicador. Ainda assim, há estratégia de equivalência comentada por Baker ([1992] 2018) na estrutura da informação, na relação dado-novo. Ademais, o deslocamento com imperativo no novo final supõe que o visitante vai para o giroscópio, após a leitura.

\section{Conclusão e perspectivas}

Ao verificar empregos de estratégias de equivalência da tradução 'normal' nas reescritas simplificadas do nosso corpus, acreditamos que nossos achados confirmam a aproximação entre tradução, TI e simplificação, além de ilustrar o processo envolvido. A explicitação dos procedimentos e um balanço entre vantagens e desvantagens da reescrita servem para entender como se dá o esforço do redator para que a informação possa ser mais acessível.

Como limitação, nem sempre é possível obter uma formulação textual completamente facilitada, sem algum traço complicador. Afinal, é preciso respeitar autoria, conteúdo e natureza do texto-fonte, que muitas vezes traz temas per se complexos. Ainda assim, ao situar essa (re)escrita, localizamos seus elementos pontuais, condicionados por cada texto, e mostramos que as estratégias tradutórias de Baker ([1992] 2018) são úteis também à crítica da simplificação.

TradTerm, São Paulo, v.37, n. 1, janeiro/2021, p. 30-63

Número Especial - Linguística de Corpus www.revistas.usp.br/tradterm 
Encontramos a tradução por paráfrase com o uso de uma palavra relacionada, mesmo que essa palavra adquira uma forma diferente da do texto original, por exemplo, 'Estados Unidos' e 'americanos'. Acima da palavra, equivalência de fraseologismos. Nas paráfrases, vimos locuções verbais, nominais, adjetivas e adverbiais em substituição aos itens do texto original, procedimentos que podem reforçar a ATT, já que advérbios e adjetivos tendem a ser complicadores.

No nível do texto, identificamos a extraposição e a mudança de voz passiva para ativa. Quanto à equivalência semiótica, observamos a complementaridade entre o escrito e o elemento concreto. E, mesmo sem explorar a equivalência pragmática, ela permeia todos os outros níveis, podendo ser apontada, por exemplo, em meio à decisão do fecho do texto sobre o giroscópio, com novos dados e um ordenamento.

Assim, acreditamos que a promoção da ATT, para diferentes públicos, associada à ideia da $\mathrm{TI}$, são assuntos que merecem atenção, tanto em LC, quanto em Estudos de Tradução e de Terminologia. 0 processo de simplificação, ilustrado aqui, mostra-se variado, rico e complexo. Como a 'tradução normal', implica escolhas, critérios de decisão, julgamentos de adequação, questões como fidelidade e limites de interferência. Afinal, o que se produz sempre será condicionado por algum sentido de responsabilidade que o redator-tradutor assume, consciente ou inconscientemente, em meio a esse cenário comunicativo.

TradTerm, São Paulo, v.37, n. 1, janeiro/2021, p. 30-63

Número Especial - Linguística de Corpus www.revistas.usp.br/tradterm 


\section{Agradecimentos}

Ao PPG-LETRAS-UFRGS, ao CNPq, à CAPES e à FAPERGS pelos apoios. À PUCRS e MCT-PUCRS pelo material para estudo.

\section{Referências}

AluísIo, S. M.; GASPERIN, C. Fostering Digital Inclusion and Accessibility: The PorSimples Project for Simplification of Portuguese Texts. In: Proceedings of the NAACL HLT 2010. Young Investigators Workshop on Computational Approaches to Languages of the Americas. New York: ACL, V.1, 2010, p. 46-53.

Alva-Manchego, F.; Martin, L.; Bordes, A.; Scarton, C.; Sagot, B.; Specia, L. ASSET: A Dataset for Tuning and Evaluation of Sentence Simplification Models with Multiple Rewriting Transformations. Research Gate, Preprints, 2020.

Anthony, L. AntConc (Version 3.5.8) [Computer Software]. Tokyo, Japan: Waseda University, 2020. Disponível em: http://www.laurenceanthony.net/software. Acesso em 30 de março de 2020.

BAKER, M. In Other Words: A Coursebook on Translation. 3a edição. Londres: Routledge, [1992] 2018.

Benedetti, I; Sobral, A. Conversas com tradutores. São Paulo: Parábola, 2003.

Berber Sardinha, T. Linguística de Corpus. Barueri - SP: Manole, 2004.

Berber Sardinha, T.; Moreira Filho, J. L.; Alambert, E. The Brazilian Corpus: An one-billion word online resource. 2009.

BouRIGAULT, D.; SLodzIAN, M. Por uma terminologia textual. In: Krieger e Araújo (orgs.). Cadernos de Tradução. Porto Alegre: Instituto de Letras, Universidade Federal do Rio Grande do Sul, p.29-32, 2004.

CASELI, H. Alinhamento sentencial de textos paralelos português-inglês. 2005. 101 f. Dissertação (Mestrado em Ciências da Computação e Matemática Computacional) - Instituto de Ciências Matemáticas e da Computação, USP, 2005.

Caseli, H. M.; Pereira, T. F.; Specia, L.; Pardo, T.A.S.; Gasperin, C.; Aluísio, S. M. Building a Brazilian Portuguese parallel corpus of original and simplified texts. In: $10^{\text {th }}$ Conference on Intelligent Text Processing and Computational Linguistics (CICLing-2009), 2009, Mexico City.

TradTerm, São Paulo, v.37, n. 1, janeiro/2021, p. 30-63

Número Especial - Linguística de Corpus

www.revistas.usp.br/tradterm 
Advances in Computational Linguistics, Research in Computer Science, 2009. v. 41. p. 59-70.

CIAPUSCIO, G. E. Textos especializados y terminología. Barcelona: IULA, 2003.

CRUSE, D. A. Lexical Semantics. Cambridge: Cambridge University Press, 1986.

CUNHA, A.L.V. DA. Coh-Metrix-Dementia: análise automática de distúrbios de linguagem nas demências utilizando Processamento de Línguas Naturais. 2015. 151f. Dissertação. (Mestrado em Ciências da Computação e Matemática Computacional) - Instituto de Ciências Matemáticas e da Computação, USP, 2015.

DeRRIDA, J. Torres de Babel. Trad. Junia Barreto, Belo Horizonte: Editora UFMG, [2002] 2006.

DuBay, W. H. The Principles of Readability. 25 August 2004. Disponível em: http://www.impact-information.com/impactinfo/readability02.pdf. Acesso em: 27 março 2020.

Eco, U. Quase a mesma coisa. Experiências de tradução. São Paulo: Record, 2007.

FinatTo, M. J. B.; MotTA, E. Terminologia e Acessibilidade: novas demandas e frentes de pesquisa. Revista GTLex, v. 2, n. 2, jan. 2019, pp. 316-356.

RodRIGUeS, E. DOS S; FREITAS, C.; QUentAL, V. Análise de inteligibilidade textual por meio de ferramentas de processamento automático do português: avaliação da Coleção Literatura para Todos. Letras de Hoje (Impresso), v. 48, p. 91-99, 2013.

HallidaY, M. An Introduction to Functional Grammar. Londres: Edward Arnold. 1985.

Hartmann, N.; Cucatto, L.; Brants, D.; Aluísio, S. Automatic Classification of the Complexity of Nonfiction Texts in Portuguese for Early School Years. In: Silva, J.; Ribeiro, R.; Quaresma, P.; Adami, A.; Branco, A. (Ed.). Computational Processing of the Portuguese Language: 12th International Conference (PROPOR-2016). [S.l.]: Springer International Publishing, 2016. p.12-24.

Heiderman, W. Prefácio. In: Heiderman, W.(org). Clássicos da teoria da tradução. 2.ed. Florianópolis: UFSC, 2010.

JAKOBSON, R. On linguistic aspects of translation. In: VENUTI, L. The Translation Studies Reader. London: Routledge, 113-118, 2000 [1959]

JakoBson, R. Linguística e Comunicação. 19a ed. São Paulo: Cultrix, [1969] 2003.

TradTerm, São Paulo, v.37, n. 1, janeiro/2021, p. 30-63

Número Especial - Linguística de Corpus

www.revistas.usp.br/tradterm 
KRIEger, M. G.; FInATto, M. J. B. Introdução à Terminologia: teoria \& prática. São Paulo: Contexto, 2004. v. 1.

LELLIS, J. Alinhamento sentencial: uma ferramenta para o tratamento automático da língua natural. 2017. 33 f., il. Trabalho de Conclusão de Curso (Bacharelado em Línguas Estrangeiras Aplicadas) Universidade de Brasília, Brasília, 2017.

Magalhães, C. M.; CAStro, M.C.; Montenegro, M.S. 2013. Estilística tradutória: um estudo de corpus paralelo de uma tradução brasileira e uma tradução portuguesa de Heart of darkness. TradTerm, v. 21:11-29.

Magalhães, C. M.; BlaUth T. P. Estilo do tradutor: um estudo do uso do itálico, palavras estrangeiras e itens culturais específicos por seis tradutores do português de Heart of Darkness. In: Tagnin S. E. O; Viana, V. Corpora na tradução. São Paulo: Hub Editorial, 2015.

MENDES, E. A. M. Processos de tradução intralingual. In: Congresso Internacional da ABRALIN, 2009, João Pessoa. Anais do VI Congresso Internacional da ABRALIN. São Paulo: Editora Ideia, 2009, V. I, p. 1161-1170.

MundaY, J. Introducing Translation Studies: Theories and Applications. $3^{a}$ edição. Londres/Nova York: Routledge, 2012.

PASQUALINI, B. Corpop: um corpus de referência do português popular escrito do Brasil. 2018. 250 p. Tese (Doutorado em Letras) - Instituto de Letras, Universidade Federal do Rio Grande do Sul, Porto Alegre, 2018.

SCHREINER, P. Alinhamento léxico utilizando técnicas híbridas discriminativas e de pós-processamento. 2010. 66p. Dissertação (Mestrado em Computação) - Universidade Federal do Rio Grande do Sul, Porto Alegre, 2010.

SILVA, A. D. C. Textos de divulgação para leigos sobre o transtorno do estresse pós-traumático em português: alternativas para a acessibilidade textual e terminológica. 2018. 427f. Dissertação (Mestrado) Programa de Pós-Graduação em Letras, Universidade Federal do Rio Grande do Sul, Porto Alegre, 2018.

TCACENCO, L. M. Análise do tratamento terminológico dos textos do Museu de Ciências e Tecnologia da PUCRS e sua relação com a situacionalidade. Cadernos do I.L., Porto Alegre, v. 2, 2019, pp.1-369.

TAGNIN, S. E. O. A linguística de corpus na e para a tradução. In: Tagnin S. E. O; Viana, V. Corpora na tradução. São Paulo: Hub Editorial, 2015.

Tarallo, F. Aspectos sociolingüísticos da tradução. Tradução e Comunicação 4. São Paulo: Álamo, 1984, p. 91-106.

TradTerm, São Paulo, v.37, n. 1, janeiro/2021, p. 30-63

Número Especial - Linguística de Corpus

www.revistas.usp.br/tradterm 
TERMINGNONI, S. Bases teórico-metodológicas para um hiperdicionário semibilíngue de expressões idiomáticas italiano-português em meio a um ambiente virtual de aprendizagem. $432 \mathrm{f}$. Tese (Doutorado em Letras). Universidade Federal do Rio Grande do Sul, Porto Alegre. 2015.

TOURY, G. Descriptive Translation Studies and Beyond. Amsterdam: John Benjamins Publishing, 1995.

TraVAGLIA, N. Tradução Retextualização. Uberlândia, EDUFU, 2003.

VAn LeEUWEN. T. Introducing Social Semiotics. Routledge, Londres e New York. 2005.

Viana, V; TAGnin, S. E. O. (Org.) Corpora na Tradução. São Paulo: Hub Editorial, 2015.

Zavaglia, C.; Ferraresi, M. A. Construção de um corpus paralelo e alinhado português-italiano-português para 0 domínio literário. Estudos Linguísticos, XXXV, 2006, pp. 502-511.

ZethSEN, K. K. Intralingual translation: an attempt at description. Meta, Montreal - Canadá, 54 (4). pp. 795-812, 2009.

Zethsen, K. K.; HILl-Madsen, A. Intralingual Translation and Its Place within Translation Studies - A Theoretical Discussion, Meta, Montreal Canadá, Déc. (2016). 61(3), pp. 692-708.

Recebido em: 31/03/2020

Aceito em: 22/09/2020

Publicado em janeiro de 2021

TradTerm, São Paulo, v.37, n. 1, janeiro/2021, p. 30-63

Número Especial - Linguística de Corpus www.revistas.usp.br/tradterm 